\title{
SPECIFIC FEATURES OF JOINT SPACE IN PATIENTS WITH PHYSIOLOGICAL OCCLUSION ON COMPUTED TOMOGRAM HEAD IMAGE
}

Article history: Submitted 15 April 2019 Accepted 8 July 2019

\section{Vladimir Shkarin', Vasily Grinin', Ruslan Halfin', Sergey Dmitrienko ${ }^{4}$, Dmitry Domenyuk ${ }^{5^{*}}$}

\author{
${ }^{1}$ Department of public health and postgraduate education, Volgograd \\ state medical university, Volgograd, Russia \\ ${ }^{2}$ Department of Public Health and Health Care, First Sechenov Moscow \\ State Medical University, Moscow, Russia \\ ${ }^{3}$ Graduate School of Health Management, First Sechenov Moscow State \\ Medical University, Moscow, Russia \\ ${ }^{4}$ Department of Dentistry, Pyatigorsk Medical-Pharmaceutical Institute \\ (Branch of Volgograd State Medical University, Pyatigorsk, Stavropol \\ Region, Russia \\ ${ }^{5}$ Department of General Dentistry and Child Dentistry, Stavropol State \\ Medical University, Stavropol, Russia
}

*Corresponding Author:domenyukda@mail.ru

The biomechanics of the lower jaw movement is subject to the articulation laws, which follow the temporomandibular joint morphology. The major elements of the joint bone structures include the temporal bone articular fossa and the articular head of the mandible condylar process. The lower jaw articular heads have an ellipsoid shape, elongated in the horizontal (transverse) direction. The articular heads axes are directed toward the large occipital foramen and, when crossing, shape an angle with a very variable magnitude $[3,4,8]$. Numerous studies have proven the relationship between the articular heads shape and the dental arches. Modern classifications for dental arch shapes distinguish gnathic and dental types, which differ in their morphometric parameters. It is a proven fact that pathological occlusion has an effect on the location of the temporomandibular joint elements and the tactics for complex treatment $[1,2,5,6,7,10]$. The main methods for studying the temporomandibular joints include radiography, where the most objective one is the method of cone-beam computed tomography $[6,9,11,12]$. The software of the tomographs available nowadays allows measuring angular and linear parameters of various structures comprising the craniofacial complex. Tomogram image sections construct articular heads' transversal axes and then the angle of their intersection is measured. However, we could find no data on the methods for linear measure- ments of inter-articular relationships, which was the purpose of this work.

to develop a method for constructing an articular triangle on head CT transversal sections, which would allow assessing the spatial location of the mandible articular heads.

\section{MATERIALS AND METHODS}

Cone-beam computed tomography (cephalostat PaX-i3D SC, VATECH Global) was employed to carry out a survey involving 28 people (both males and females) in their first period of mature age with a full set of permanent teeth and an orthognathic bite. The CT sections passing through the mandible articular heads were used to make measurements using landmarks represented as dots and lines. The articular heads had the medial and lateral poles of the ellipse marked on them, which were interconnected with a straight line thus producing the articular heads longitudinal axis. The obtained marks were further used to develop a research method.

\section{RESULTS AND DISCUSSION}

The method for constructing an articular triangle implied connecting the longitudinal axes of the articular heads thus shaping the apex of the triangle. The base of the triangle was a line connecting the articular heads' lateral poles. The proposed method allowed measuring the distance between the articular heads in millimeters as well as measuring the articular heads angle. In case of physiological occlusion, all the examined articular triangles, as a rule, were equilateral. In addition, the proposed method allowed us to measure the triangle height and calculate its area as the product of half the inter-articular distance by the articular triangle height. The proposed method of constructing an articular triangle will help understand the articulation laws and identify the dental system individual specifics. The data can be used in orthopedic dentistry when designing artificial dental arches.

\section{CONCLUSION}

Given the above, the shape of the articular triangle can be used when selecting a method for treating 
occlusion anomalies in the transversal direction, for diagnosing anomalies of the articular heads location, and for evaluating their symmetrical spatial arrangement.

\section{REFERENCES}

1. Borodina V.A., Domenyuk D.A., Veisgeim L.D., DMITRIENKo S.V. Biometry of permanent occlusion dental arches - comparison algorithm for real and design indicators. Archiv EuroMedica, 2018; Vol. 8; 1: 25-26. https://doi.org/10.35630/2199$885 \mathrm{X} / 2018 / 8 / 1 / 25$

2. Dmitrienko S.V., Domenyuk D.A., KochkonYAN A.S., Karslieva A.G., DMitriENKo D.S. Interrelation between sagittal and transversal sizes of maxillary dental arches. Archiv EuroMedica, 2014; Vol. 4; 2: 10-13.

3. Dmitrienko S.V., Davydov B.N., V.V. ShKarin, DoMeNYuk D.A. Algorithm for determining the size of artificial teeth by the morphometric parameters of the face in people with full adentia. Dentistry. 2018; 97(6): 57-60.

4. Domenyuk D.A., Vedeshina E.G., Dmitrienko S.V. Efficiency evaluation for integrated approach to choice of orthodontic and prosthetic treatments in patients with reduced gnathic region. Archiv EuroMedica, 2015; Vol. 5; 2: 6-12.

5. Domenyuk D.A., Shkarin V.V., Porfiriadis M.P., DMitrienko D.S., DMitrienko S.V. Algorithm for forecasting the shape and size of dent arches front part in case of their deformations and anomalies. Archiv EuroMedica, 2017; Vol. 7; 2: 105-110.

6. ShKarin V.V., DaVydov B.N., DomenYuk D.A., DMITRIENKo S.V. Non-removable arch orthodontic appliances for treating children with congenital maxillofacial pathologies - efficiency evaluation. Archiv EuroMedica, 2018; Vol. 8; 1: 97-98. https://doi. org $/ 10.35630 / 2199-885 \mathrm{X} / 2018 / 8 / 1 / 97$

7. Domenyuk D.A., LePILIN A.V., Fomin I.V., DMitrienko S.V. Improving odontometric diagnostics at jaw stone model examination. Archiv EuroMedica, 2018; Vol. 8; 1: 34-35. https://doi. org $/ 10.35630 / 2199-885 X / 2018 / 8 / 1 / 34$

8. KorobkeEv A.A., Domenyuk D.A., SHKarin V.V., DMITRIENKo S.V. Types of facial heart depth in physiological occlusion. Medical news of North Caucasus. 2018. - Vol. 13. - № 4. - P. 627-630. (In Russ., English abstract). DOI - https://doi.org/10.14300/ mnnc.2018.13122

9. LepiLin A.V., Fomin I.V., Domenyuk D.A., Dmitrienko S.V. Diagnostic value of cephalometric parameters at graphic reproduction of tooth dental arches in primary teeth occlusion. Archiv EuroMedica, 2018; Vol. 8; 1:37-38. https://doi. org/10.35630/2199-885X/2018/8/1/37

10. Shkarin V., Domenyuk D., Lepilin A., Fomin I., Dmitrienko S. Odontometric indices fluctuation in people with physiological occlusion. Archiv EuroMedica, 2018; Vol. 8; 1: 12-18. https://doi. org $/ 10.35630 / 2199-885 \mathrm{X} / 2018 / 8 / 1 / 12$
11. Korobkeev A. A., Domenyuk D. A., ShKarin V. V., DMitrienko S. V., Mazharov V. N. Variability of odontometric indices in the aspect of sexual dimorphism. Medical News of North Caucasus. 2019;14(1.1):103-107. DOI - https://doi. org/10.14300/mnnc.2019.14062 (In Russ.)

12. Dmitrienko T.D., Domenyuk D.A., PorfyriaDIS M.P., ARUTYUNOVA A.G., KoNDRATYUK A.A., Subbotin R.S. Connection between clinical and radiological torque of medial incisors at physiological occlusion. Archiv EuroMedica, 2019; Vol. 9; 1:29-37. https://doi.org/10.35630/2199$885 \mathrm{X} / 2019 / 9 / 1 / 29$ 